\title{
Measurement on Thermal Conductivity of Pine Wood Dust Filled Epoxy Composites
}

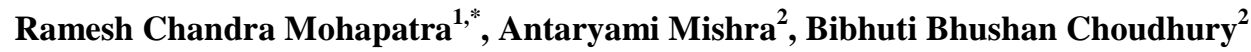 \\ ${ }^{1}$ Government College of Engineering, Keonjhar, India \\ ${ }^{2}$ Indira Gandhi Institute of Technology, Sarang, India \\ *Corresponding author: rameshmohapatra75@gmail.com
}

Received July 14, 2014; Revised August 25, 2014; Accepted September 04, 2014

\begin{abstract}
In the present investigation the thermal conductivity of composites of epoxy reinforced with pine wood dust (PWD) at different volume fractions are determined experimentally by using Lee's apparatus. The composites have been prepared by using hand-lay-up technique. The principle of heat transfer by conduction through a bad conductor is equal to the quantity of heat transfer by radiation from the metallic disc has been applied. The experimental results show that the incorporation of pine wood dust results in reduction of thermal conductivity of epoxy resin and there by improves its thermal insulation capability. Experimental results are compared with Rule of mixture model, Maxwell model, Russell model and Wood side \& Baschirow \& Selenew to describe the variation of thermal conductivity versus the volume fraction of the fibre. All these models exhibited results close to each other at low dust content. It has been found that the errors associated with these models with respect to experimental ones lie in the range of 0.6 to $28.6 \%, 53.2$ to $58.7 \%, 55.45$ to $63.47 \%$ and 34.21 to $47.06 \%$ respectively. With addition of 6.5 Vol. \%, 11.3 Vol. \%, 26.8 Vol. \% and 35.9 Vol.\% of pine wood dust the thermal conductivity of neat epoxy resin was reduced by about $39.4 \%, 43.8 \%, 54 \%$ and $58.1 \%$ respectively.
\end{abstract}

Keywords: Lee's apparatus, Epoxy-Pine wood dust composite, thermal conductivity, error analysis

Cite This Article: Ramesh Chandra Mohapatra, Antaryami Mishra, and Bibhuti Bhushan Choudhury, "Measurement on Thermal Conductivity of Pine Wood Dust Filled Epoxy Composites." American Journal of Mechanical Engineering, vol. 2, no. 4 (2014): 114-119. doi: 10.12691/ajme-2-4-3.

\section{Introduction}

Incorporation of natural fibers in to polymer is now a standard technology to improve the insulating and mechanical properties of polymer. Now adays, the fibres resulting from wood, animals, leaves, grasses and other natural sources are commonly used as reinforcement in composites used for various applications, like automotive (interior and exterior), buildings, shipping and packaging industries etc. due to their unusual properties compared to other synthetic fibres. Advances in manufacturing techniques in natural fibre-reinforced composites have allowed the car industry to utilise these composites in interior trimmings. Besides the environmental benefits, compared to glass fibre composites, the natural fibre reinforced composites with the equivalent performances have higher fibre content, resulting in less pollution from synthetic polymer matrix, and much lighter weight, reducing the amount of driving fuel in automotive applications. There are many application of natural fibre composite in every day life. For example, jute is a common reinforcement for composites in India. Jute fibers with polyester resins are used in buildings, elevators, pipes, and panels. Natural fiber composites can also be very cost effective material for application in building and construction areas (e.g. walls, ceiling, partition, window and door frames), storage devices (e.g. bio-gas container, post boxes, etc.), furniture (e.g. chair, table, tools, etc.), electronic devices (outer casting of mobile phones), automobile and railway coach interior parts (inner fenders and bumpers), toys and other miscellaneous applications (helmets, suitcases). During the last few years, a series of research works have been done to replace the conventional synthetic fiber with natural fiber composites. For instant, hemp, sisal, pine, teak, jute, cotton, flax and broom are the most commonly fibers used to reinforce polymers like polyolefins, polystyrene and epoxy resins. In addition, fibers like sisal, jute, coir, oil palm, bamboo, bagasse, wheat and flax straw, waste silk and banana have proved to be good and effective reinforcement in the thermoset and thermoplastic matrices.

\section{Review of Literature}

Effective thermal conductivity is an important characteristic of heat transfer properties of materials. The temperature field in composite materials cannot be determined unless the thermal conductivities of the media are known. Numerous theoretical and experimental approaches have been developed to determine the precise value of this parameter. Russell [1] developed one of the early model systems using the electrical analogy, assuming that the discrete phase is isolated cubes of the 
same size dispersed in the matrix material and that the isothermal lines are planes. Maxwell [2] studied the effective thermal conductivity of heterogeneous materials. The effective thermal conductivity of a random suspension was determined for sphere within a continuous medium by solving Laplace's equation. Baschirow and Selenew [3] developed the equation for the case when the particles are spherical and the two phases are isotropic. In real composite material, the isothermal surfaces present a very complex shape and cannot be analytically determined. The models used to calculate thermal conductivities are thus highly simplified models of the real media.Stein hagen [4] reviewed the thermal conductivity of wood from $-40^{\circ} \mathrm{C}$ to $100^{\circ} \mathrm{C}$ and found that thermal conductivity of wood increases in a linear manner with temperature and density. Little difference was found between its value in tangential and radial directions. Yu et al. [5] measured the thermal conductivity of polystyrene-aluminium nitride composite and found that the thermal conductivity of the composites was higher for a polystyrene particle size of $2 \mathrm{~mm}$ than that of a particle size of $0.5 \mathrm{~mm}$. Fu et al. [6] predicted the effective thermal conductivity of short fibre rein-forced polymer composites. It was observed that the thermal conductivity of the composites increases with (increase or decrease) in mean fibre length but decreases with mean fibre orientation angle with respect to the measured direction. Behzad and Sain [7] determined the thermal conductivity of the hemp fibre reinforced polymer composite at different volume fractions of the fibre. To confirm the experimental results, the heating experiments are simulated by a finite element model (FEM) using the thermal conductivity values obtained from the experiment and found good agreement between the obtained results and models. Han et al. [8] investigated the thermal conductivity of epoxy resin composites with the addition of different sizes of boron nitride $(\mathrm{BN})$ fillers. They concluded that at low and moderate filler concentrations the filler size is not of crucial importance to the thermal conductivity of the composites. Abdul Razak et al. [9] studied the electrical and thermal properties of epoxycarbon black composites. They found that the epoxycarbon black composites have better thermal properties than the neat epoxy. Singh et al. [10] developed a theoretical model for predicting effective thermal conductivity of metal filled polymer composites. Good agreement between estimated values and earlier experimental data was observed. Comparison of the proposed relation with Lewis and Neilsen's models has also been made. Mounika et al. [11] investigated the thermal conductivity experimentally by a guarded heat flow meter method. The results showed that the thermal conductivity of the composite decreased with increase in fibre content and quite opposite trend was observed with respect to temperature. Veiseh et al. [12] utilized the Artificial Neural Networks (ANN) in order to predict the effective thermal conductivity of expanded polystyrene with specific temperature and moisture content. The experimental data were used for training and testing ANN. It was found that the results obtained from the ANN method was in good agreement with experimental data. Qi et al. [13] investigated the thermal conductivity of composite panels hot- pressed with varying proportions of sweet sorghum and high density poly ethylene (HDPE). The results showed that the thermal conductivity increases in a linear manner with temperature and density but in a non linear manner with HDPE content. Prisco [14] investigated experimentally the thermal conductivity of wood flour (WF) filled high density polyethylene composite (Wood plastic composite, WPC). Experimental results showed that the thermal conductivity of the composite decreases with the filler content and WF content. Dewangan et al. [15] developed a simple 3-D finite element model to predict the thermal conductivity of polyester composite filled with micro sized rice husk particle which is biodegradable and having good potential of natural reinforcement. The simulation was compared with measured effective thermal conductivity value obtained from other established correlation such as Rule of Mixture, Maxwell models and Russel model. They also found that the effective thermal conductivity of polyester composite decreased with the increase of filler concentration. Reddy et al [16] studied the thermal conductivity of cow dung filled glass-polyester hybrid composite as a function of cow dung powder content. The thermal conductivity of cow dung filled glass-polyester hybrid component was found to be lower than the glass fiber reinforced composite.

\section{Scope/Objectives}

Keeping above review in mind an attempt has been made in the present work to develop composites of epoxy with varying content of pine wood dust. The objectives of this investigation are

1. Thermal conductivity measurements using Lee's apparatus

2. Results obtained may be compared with that found from various theoretical models.

3. Finally error percentage is to be estimated for experimental findings for each composite with respect to theoretical values.

\section{Thermal Conductivity Models}

Many theoretical and empirical models have been proposed to predict the effective thermal conductivity of two phase mixtures. For a two component composite the simplest alternative would be with the materials arranged in either parallel or series with respect to heat flow, which gives the upper and lower bounds of effective thermal conductivity as explained in Eqns. 1 and 2.

Series Model (Rule of Mixture):

$$
\frac{1}{K_{c}}=\frac{1-\varphi}{K_{m}}+\frac{\varphi}{K_{f}}
$$

Where c- composite, m- matrix, f-filler, $\Phi$ - volume fraction of filler and K-Thermal conductivity

Parallel model:

$$
K_{c}=(1-\varphi) K_{m}+\varphi K_{f}
$$

Where $K_{C}$ - Thermal conductivity of composite, $\mathrm{K}_{\mathrm{m}}$ Thermal conductivity of matrix, $\mathrm{K}_{\mathrm{f}}$ - Thermal conductivity of filler and $\Phi$ - is the volume fraction of the filler. Most of the experimental results were found to fall in between the two models. However the lower bound model is usually closer to the experimental data compared to the rule of 
mixture, which brought to a number of different models derived from the basic series model.

\section{Russel model:}

Russel [1] developed one of the early model systems using the electrical analogy. Assuming that the discrete phase is isolated cubes of the same size dispersed in the matrix material and that the isothermal lines are planes, an equation for the thermal conductivity of the composite was derived using a series parallel network.

$$
K_{c}=K_{m}\left[\frac{\varphi^{\frac{2}{3}}+\frac{K_{m}}{K_{f}}\left(1-\varphi^{\frac{2}{3}}\right)}{\varphi^{\frac{2}{3}}-\varphi+\frac{K_{m}}{K_{f}}\left(1+\varphi-\varphi^{\frac{2}{3}}\right)}\right]
$$

\section{Maxwell model:}

Maxwell [2] developed first theoretical model for two phase system. Effective thermal conductivity of composite is derived by considering spherical fillers dispersed in a continuous matrix randomly. He assumed that these fillers are distributed into the matrix having no thermal interaction with each other. The derived equation is:

$$
K_{c}=K_{m}\left[\frac{K_{f}+2 K_{m}+2 \varphi\left(K_{f}-K_{m}\right)}{K_{f}+2 K_{m}-\varphi\left(K_{f}-K_{m}\right)}\right]
$$

\section{Baschirow and Selenew model:}

Baschirow and Selenew [3] developed the following equation for the case when the particles are spherical and two phases are isotropic:

$$
K_{c}=K_{m}\left[1-\frac{a^{2} \pi}{4}+\frac{a \cdot \pi \cdot p}{2}\left\{1-\frac{p}{a} \ln \left(1+\frac{a}{p}\right)\right\}\right]
$$

Where

$$
p=\frac{K_{f}}{K_{m}-K_{f}}, a=\left(\frac{6 \varphi}{\pi}\right)^{\frac{1}{3}}
$$

\section{Experimental Details}

\subsection{Materials}

Epoxy (LY 556) resin and the corresponding hardener (HY 951) were mixed in a ratio of $10: 1$ by weight supplied by Hindustan Ciba Geigy (India) Ltd. Pine wood dust has been chosen as the filler material mostly for its very low thermal conductivity $\left(0.068 \mathrm{~W} / \mathrm{m}^{-}{ }^{-} \mathrm{K}\right)$ and low density $(0.52 \mathrm{gm} / \mathrm{cc})$. It is also renewable, eco-friendly, available at low cost, non toxic and basically considered as a waste product.

\subsection{Composite Preparation}

To prepare the composite samples for measurement of thermal conductivity using Lee's apparatus a mould of $110 \mathrm{~mm}$ diameter and $5 \mathrm{~mm}$ thickness was made from a stainless steel sheet. This mould was placed in inverted position over a Mylar sheet placed at the bottom of the mould. The mould was coated with wax and silicon spray was used as releasing agent for easy removal of the sample. The low temperature curing epoxy resin and corresponding hardener were mixed in a ratio of 10:1 by weight as recommended. Pine wood dust (PWD) particles with average size $150 \mu \mathrm{m}$ were reinforced in epoxy resin (density $1.1 \mathrm{gm} / \mathrm{cc}$ ) to prepare the composites. The fabrication of these composite slabs was done by conventional hand - lay - up technique. The cast composite was cured under a load of about $50 \mathrm{~kg}$ for 24 hours before it was removed from the mould. Then this cast was post cured in air for another 24 hours. The specimens were prepared having dimension of $110 \mathrm{~mm}$ diameter with thickness of $5 \mathrm{~mm}$.

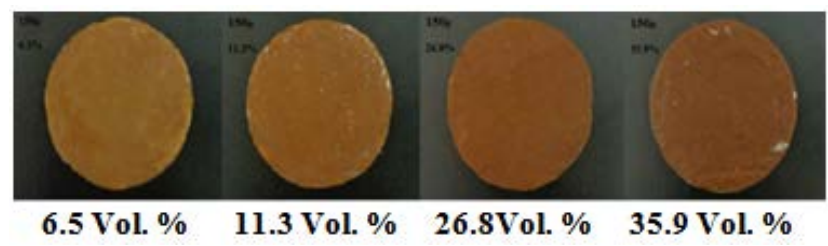

Figure 1. Specimens with varying percentage of wood dust

\subsection{Experimental Set Up}

The thermal conductivity test is carried out with Lee's disc apparatus as shown in Figure 2. The Nickel disc (N) is hung from the stand with the help of three strings. A heating chamber $(\mathrm{H})$ with facility of passage of steam in and out is created. Metallic disc (M) is placed on the top of a heating chamber $(\mathrm{H})$. Sample disc $(\mathrm{S})$ is placed in between metal disc and nickel disc. Two holes are made in the nickel disc (N) and metallic disc (M) for the insertion of thermometers to measure the temperature. The experimental set up is also shown in Figure 3.

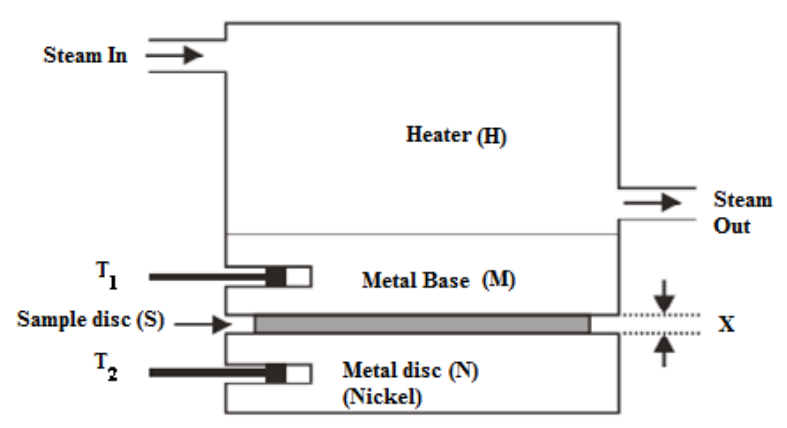

Figure 2. Schematic diagram of Lee’s disc Apparatus.

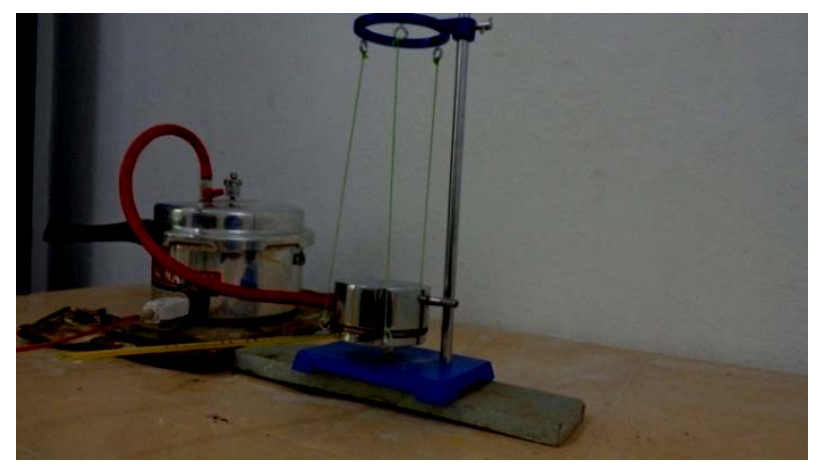

Figure 3. Experimental set up of Lee' disc Apparatus

\subsection{Working Procedure}

Initially mass of the nickel disc (N) was measured using a balance. Diameter of the specimen was found out using Vernier Caliper and the thickness was measured using a screw gauge. After this 
- The heater $(\mathrm{H})$ was started by sending steam through the heating chamber. The temperatures $T_{1}$ and $T_{2}$ were recorded at a regular interval of 5 minutes till they reached the steady state.

- Then, the supply of steam was cut off and nickel disc (N) and specimen or sample disc (S) were removed. Heat was supplied to the nickel $\operatorname{disc}(\mathrm{N})$ along with the sample(S) with the help of Bunsen burner (shown in Figure 4) so that nickel disc along with sample is heated to a temperature $10^{\circ} \mathrm{C}$ above the steady state temperature $T_{2}$. After that the Bunsen burner was removed and allowed the nickel disc $(\mathrm{N})$ to cool. Temperatures were noted in every half a minute until the temperature falls about $10^{\circ} \mathrm{C}$ from steady state temperature $T_{2}$.

- Variation of temperature of Nickel disc with time of cooling was plotted as shown in Figure 5. A tangent is drawn at the steady state temperature $T_{2}$. Thus the slope of this tangent gives the rate of cooling $\partial T / \partial t$ at steady state temperature $T_{2}$.

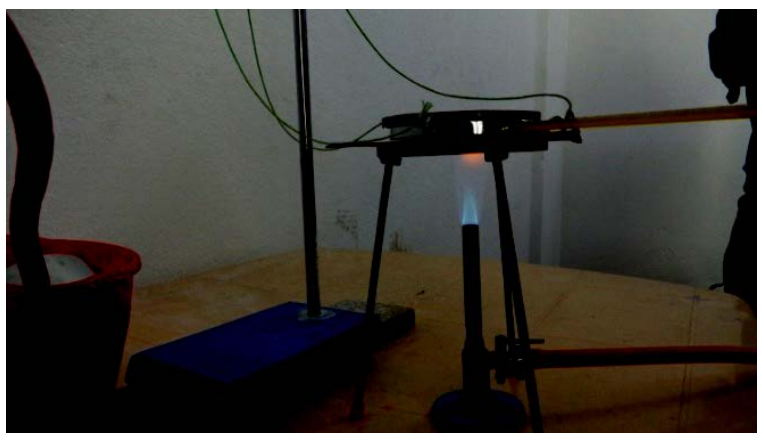

Figure 4. Supply of heat to the disc by Bunsen burner

\section{Thermal Conductivity Measurement}

Thermal conductivity is a material property that describes the rate at which the heat flows within a body for a given temperature change.

The rate of heat conducted through the specimen or sample is

$$
Q=K A\left(T_{1}-T_{2}\right) / L
$$

Where, $\mathrm{L}$ is the thickness of the sample, $\mathrm{A}$ is the area of cross section of the sample, $\mathrm{K}$ is the thermal conductivity, $\mathrm{Q}$ is the rate of heat transfer and $\left(\mathrm{T}_{1}-\mathrm{T}_{2}\right)$ is the temperature difference.

The rate of heat lost by the nickel disc (N) to the surrounding under steady state is

$$
Q=m c(\partial T / \partial t)_{T_{2}}
$$

Where, $m$ is the mass of nickel disc $(\mathrm{N})$, c is the specific heat of the brass disc (B) and ( $\partial T / \partial t)$ is it's rate of cooling at $\mathrm{T}_{2}$

Comparing equations 6 and 7

$$
K=m c(\partial T / \partial t)_{T_{2}} / A\left(T_{1}-T_{2}\right) / L
$$

$(\partial T / \partial t)_{T_{2}}$ and $\left(T_{1}-T_{2}\right)$ is calculated using Lee's disc apparatus. Giving the input value of mass of nickel disc (N), specific heat of the nickel disc, thickness of the sample and area of cross section of the of the sample, the thermal conductivity is calculated.

\section{Results and Discussion}

The cooling rate of composite in terms of time temperature curve has been shown in Figure 5 . The thermal conductivity obtained from the experimental study for the particulate filled epoxy composite with varied proportion of pine wood dust (PWD) is also shown in Figure 6 . This figure shows that the incorporation of pine wood dust results in reduction of thermal conductivity of epoxy resin and there by improves its insulation capability. This reduction might have been attributed due to air voids created during preparation of composite and also the thermal conductivity of pine wood dust is less than the thermal conductivity of epoxy resin. Therefore, increasing the percentage of pine wood dust decreases the thermal conductivity of the composite. The shape of pine wood dust assumed to be spherical while in actual practice they are irregular shaped. Though the distribution of pine wood dust in the matrix body is assumed to be in an arranged manner, but it is actually dispersed in the resin almost randomly. With addition of 6.5 Vol.\%, 11.3 Vol.\%, 26.8 Vol.\% and 35.9 Vol.\% of pine wood dust, the thermal conductivity of epoxy resin dropped by 39.4\%, 43.8\%, $54 \%$ and $58.1 \%$ respectively. The values of thermal conductivities of composite with two components i.e epoxy and PWD are given in Table 1.

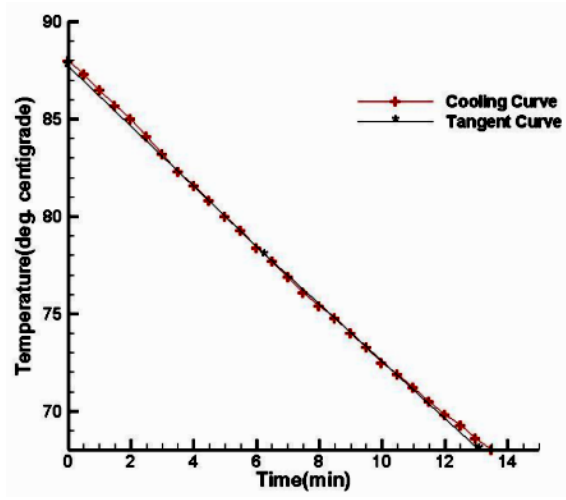

Figure 5. Cooling rate for composite (Time-Temperature curve)

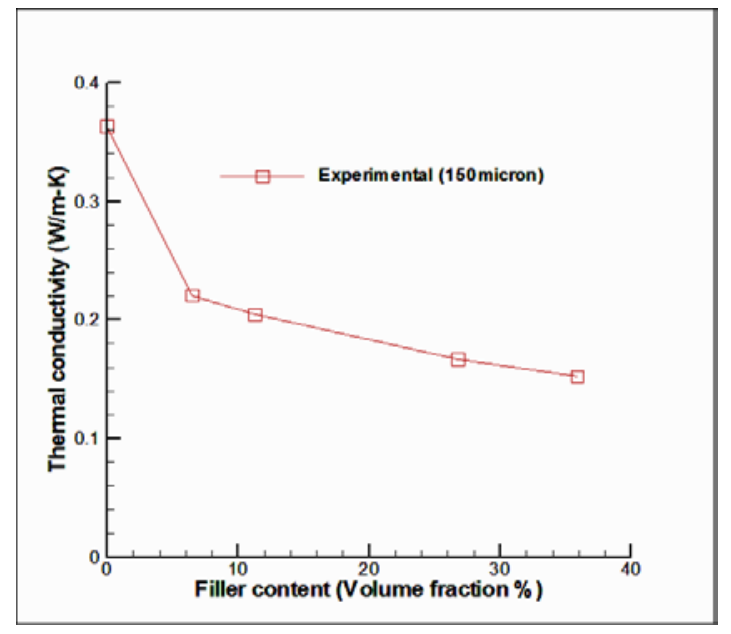

Figure 6. Thermal conductivity of epoxy composites as a function of filler content 
Table 1. Measured thermal conductivity values of composites of varied composition

\begin{tabular}{|c|c|c|c|}
\hline Sample & $\begin{array}{c}\text { Particulate } \\
\text { content } \\
\text { (Vol.\%) }\end{array}$ & $\begin{array}{c}\text { Experimental } \\
\text { value of thermal } \\
\text { conductivity } \\
\text { (W/m-K) }\end{array}$ & $\begin{array}{c}\text { \% reduction of } \\
\text { thermal conductivity } \\
\text { with respect to neat } \\
\text { epoxy }\end{array}$ \\
\hline 1 & 0(neat epoxy) & 0.363 & 0 \\
\hline 2 & 6.5 & 0.220 & 39.4 \\
\hline 3 & 11.3 & 0.204 & 43.8 \\
\hline 4 & 26.8 & 0.167 & 54.0 \\
\hline 5 & 35.9 & 0.152 & 58.1 \\
\hline
\end{tabular}

The effective thermal conductivity values obtained from the experimental work for the particulate filled epoxy composites with varied proportion of pine wood dust are compared with several thermal conductivity models as shown in Figure 7. It is noticed that the experimental results and all four models are close to each other at low fibre content. It has also been found that the thermal conductivities obtained from experiments and four theoretical models exhibited decrease with increase in the volume fraction of pine wood dust. It is further noted that Maxwell model, Russel model and Baschirow \& Selenew model overestimate the value of thermal conductivity; the Rule of mixture overestimates the value up to 26.8 volume fraction after that it underestimates with respect to the experimental one. On comparison, it has been found that the errors associated with all the above four models with respect to experimental ones lie in the range of 0.6 to
$28.6 \%, 53.2$ to $58.7 \%, 55.45$ to $63.47 \%$ and 34.21 to $47.06 \%$ respectively. The values of thermal conductivities and percentage of errors associated with each method for individual composite with two components i.e epoxy and pine wood dust are given in Table 2 and Table 3 respectively.

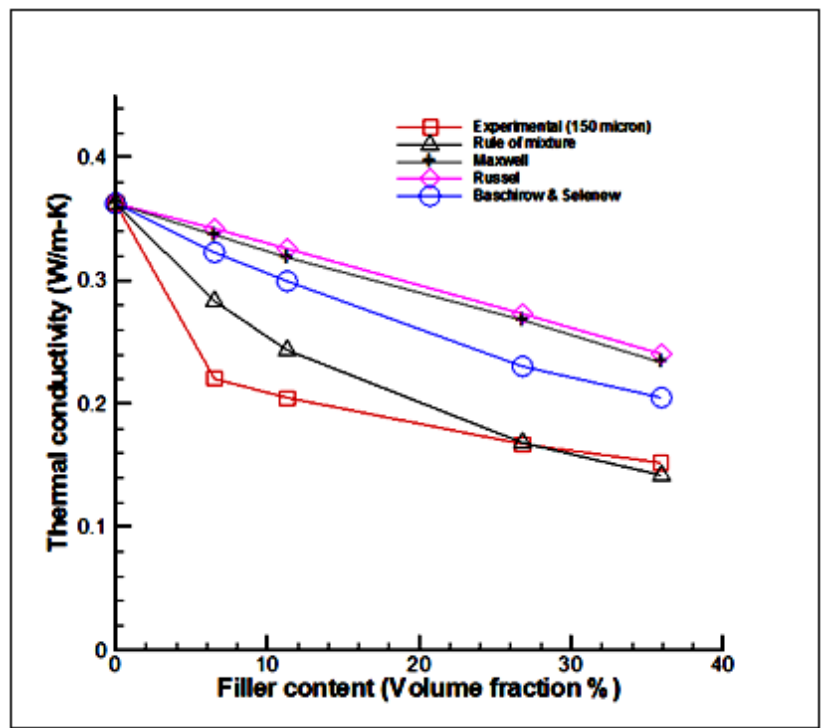

Figure 7. Comparison of thermal conductivity of different models with experimental values and varying filler content

Table 2. Thermal conductivity values of composites obtained from different methods

\begin{tabular}{|c|c|c|c|c|c|c|}
\hline \multirow{2}{*}{ Sample } & \multirow{2}{*}{ Particulate content (Vol.\%) } & \multicolumn{5}{|c|}{ Effective thermal conductivities of composites (W/m-K) } \\
\cline { 3 - 7 } & & Rule of mixture & Max-well & \multicolumn{2}{|c|}{ Russel } & \multicolumn{2}{c|}{ Baschirow \& Selenew } & Exp-erimental \\
\hline 1 & 0 (Neat epoxy) & 0.363 & 0.363 & 0.363 & 0.363 \\
\hline 2 & 6.5 & 0.283 & 0.337 & 0.342 & 0.323 \\
\hline 3 & 11.3 & 0.244 & 0.319 & 0.326 & 0.300 \\
\hline 4 & 26.8 & 0.168 & 0.265 & 0.273 & 0.230 \\
\hline 5 & 35.9 & 0.142 & 0.234 & 0.241 & 0.167 \\
\hline
\end{tabular}

Table 3. Percentage errors with respect to the experimental value

\begin{tabular}{|c|c|c|c|c|c|}
\hline \multirow{2}{*}{ Sample } & \multirow{2}{*}{$\begin{array}{c}\text { Particulate } \\
\text { content } \\
\text { (Vol.\%) }\end{array}$} & \multicolumn{4}{|c|}{$\begin{array}{l}\text { Percentage of errors with respect to the } \\
\text { Experimental value }\end{array}$} \\
\hline & & $\begin{array}{l}\text { Rule of } \\
\text { mixture }\end{array}$ & Maxwell & Russel & $\begin{array}{l}\text { Bashirow } \\
\text { \& Selenew }\end{array}$ \\
\hline 1 & $\begin{array}{l}0 \text { (Neat } \\
\text { epoxy) }\end{array}$ & 0 & 0 & 0 & 0 \\
\hline 2 & 6.5 & 28.6 & 53.2 & 55.45 & 46.82 \\
\hline 3 & 11.3 & 19.6 & 56.4 & 59.80 & 47.06 \\
\hline 4 & 26.8 & 0.6 & 58.7 & 63.47 & 37.72 \\
\hline 5 & 35.9 & 6.6 & 54.0 & 58.55 & 34.21 \\
\hline
\end{tabular}

\section{Conclusions}

The following conclusions may be drawn from the above analysis

- An environmental waste like pine wood dust can be gainfully utilized for preparation of composites.

- Composites made of PWD posses less thermal conductivity and this can be used as insulators.

- It has been found that the thermal conductivity of composites made of PWD is decreased with increase in filler content.
- Due to improved insulation capability these composites can be used for applications such as insulation boards, air craft components, ceiling of roofs, automotive components and furnitures etc.

\section{References}

[1] Russell HW. "Principles of heat flow in porous insulation.” J Am Ceram Soc. Vol.18 (1), 1935.

[2] Maxwell JC. "A Treaties on Electricity and Magnetism,” $3^{\text {rd }}$ ed. New York,: Dover; 1954.

[3] Baschirow AB, ManukianAM. Thermal conductivities of polymers at various temperatures and pressures. Mech. Polim 1974; 3: 564.

[4] Steinhagen H. P., "Thermal conductivity properties of wood, green or dry, from $-40^{\circ} \mathrm{C}$ to $+100^{\circ} \mathrm{C}$ : a literature review.” In: Gen. Tech. Re FPL-09, U.S. Department of Agriculture Forest Service, Forest products Laboratory, Madison WI., 1977.

[5] Yu, S.Z., Hing, P., and Hu, X., "Thermal Conductivity of Polystyrene-Aluminium Nitride Composite," Composites, Part AAppl. Sci. Manuf. Vol. 33(2), 2002, pp. 289-292.

[6] Fu, S. Y. and Mai, Y.W., "Thermal conductivity of misaligned short fibre reinforced polymer composites,” J. Appl. Polymer Sci., Vol.(88), 2003, pp. 1497-1505.

[7] Behzad, T. and Sain, M., "Measurement and prediction of thermal conductivity for hemp fibre reinforced composites,” Polymer Eng. Sci. Vol. 47 (7), 2007, pp. 977-83. 
[8] Han Z., Wood J. W., Herman H., Zhang C. and Stevens G. C., "Thermal properties of composites filled with different fillers," IEEE Inter. Symp. EI. Ins., 2008, pp. 497-501.

[9] Abdul Razak A. A., Salah N J. and Kazem W, A., "Electrical and thermal properties of epoxy resin filled with carbon black," Eng. \& Tech. J. Vol. 27, No. 11, 2009.

[10] Singh Ramvir and Sharma P. K.,"Effective thermal conductivity of metal filled polymer composites," Indian Journal of pure and applied physics. Vol. 49.2011, pp. 112-116.

[11] Mounika M., Ramaniah K., Prasad A.V. Ratna, Rao K. Mohana, Reddy K. Hema Chandra, Mater J.. "Thermal Conductivity Characterization of Bamboo Fiber Reinforced Polyester Composite”. Environ. Sci. 3 (6), 2012, pp. 1109-1116.

[12] Veiseh S. and Sefidgar M.. "Prediction of effective thermal conductivity of moistened insulation materials by neural network,"
Asian Journal of Civil Engineering (Building and Housing) Vol. 13 (3), 2012, pp. 319-330.

[13] Qi Chuseng, Yadama Vikram, Guo Kangquan and Wolcott Michael P., "Thermal conductivity of sorghum and sorghum-thermo plastic composite panels,” Industrial Crops and Products, Vol. 45, 2013, pp. 455-460.

[14] Prisco Umberto, "Thermal conductivity of flat-pressed wood plastic composites at different temperatures and filler content,” Science and engineering of composite materials, Vol. 0, Issue 0, 2013, pp. 1-8.

[15] Dewangan Kush Kumar, Naik Vinod and Agrawal Durga, "Numerical computational of effective thermal conductivity of polymer composite filled with rice husk particle,” IOSR Journal of Mechanical and Civil Engineering (IOSR-JMCE), 2014, pp. 12-16.

[16] Reddy T.Rajeth Kumar, Rao T. Subba and Suvarna R. Padma, "Studies on thermal characteristics of cow dung powder filled glass-polyester hybrid composites," Composites: Part B, Vol. 56, 2014, pp. 670-672. 